ACCEPTED MANUSCRIPT

\title{
ZnO nanowire sensitization with Ru polypyridyl complexes: charge- transfer probed by spectral and relaxation photocurrent measurements
}

To cite this article before publication: Nadia Celeste Vega et al 2018 Mater. Res. Express in press https://doi.org/10.1088/2053-1591/aacfa5

\section{Manuscript version: Accepted Manuscript}

Accepted Manuscript is "the version of the article accepted for publication including all changes made as a result of the peer review process, and which may also include the addition to the article by IOP Publishing of a header, an article ID, a cover sheet and/or an 'Accepted Manuscript' watermark, but excluding any other editing, typesetting or other changes made by IOP Publishing and/or its licensors"

This Accepted Manuscript is @ 2018 IOP Publishing Ltd.

During the embargo period (the 12 month period from the publication of the Version of Record of this article), the Accepted Manuscript is fully protected by copyright and cannot be reused or reposted elsewhere.

As the Version of Record of this article is going to be / has been published on a subscription basis, this Accepted Manuscript is available for reuse under a CC BY-NC-ND 3.0 licence after the 12 month embargo period.

After the embargo period, everyone is permitted to use copy and redistribute this article for non-commercial purposes only, provided that they adhere to all the terms of the licence https://creativecommons.org/licences/by-nc-nd/3.0

Although reasonable endeavours have been taken to obtain all necessary permissions from third parties to include their copyrighted content within this article, their full citation and copyright line may not be present in this Accepted Manuscript version. Before using any content from this article, please refer to the Version of Record on IOPscience once published for full citation and copyright details, as permissions will likely be required. All third party content is fully copyright protected, unless specifically stated otherwise in the figure caption in the Version of Record.

View the article online for updates and enhancements. 


\title{
ZnO nanowire sensitization with Ru polypyridyl complexes: charge-transfer probed by spectral and relaxation photocurrent measurements
}

\author{
N C Vega ${ }^{1, \#}$, Juan H Mecchia Ortiz ${ }^{2}$, M Tirado ${ }^{3}$, Néstor E. Katz ${ }^{2}$ and D Comedi ${ }^{1, *}$ \\ ${ }^{1}$ INFINOA (UNT-CONICET) and LAFISO, Departamento de Física, Facultad de Ciencias Exactas \\ y Tecnología, Universidad Nacional de Tucumán, Av. Independencia 1800, Tucumán, 4000 \\ Argentina. \\ ${ }^{2}$ INQUINOA-UNT- CONICET, Instituto de Química Física, Facultad de Bioquímica, Química y \\ Farmacia, Universidad Nacional de Tucumán, Ayacucho 471, (T4000INI) San Miguel de Tucumán, \\ Argentina \\ ${ }^{3}$ INFINOA (UNT-CONICET) and LNPD, Departamento de Física, Facultad de Ciencias Exactas y \\ Tecnología, Universidad Nacional de Tucumán, Av. Independencia 1800, Tucumán, 4000 \\ Argentina \\ Corresponding authors: \\ \# nvega@herrera.unt.edu.ar \\ * dcomedi@herrera.unt.edu.ar
}

\begin{abstract}
Dye-sensitized $\mathrm{ZnO}$ nanowire (NW) electrodes were fabricated using Ru polypyridyl complexes that use nitrile instead of carboxylic group as anchoring unit to the NW surfaces. The complexes formula is $\left[R u(\text { bpy })_{3-x}(\text { Mebpy-CN })_{x}\right]^{2+}\left(x=1-3\right.$, bpy $=2,2^{\prime}$-bipyridine, Mebpy-CN = 4-methyl-2,2'bipyridine-4'-carbonitrile). The $\mathrm{ZnO} N \mathrm{NW}$ were grown by a vapor transport method on insulating $\mathrm{SiO}_{2} / \mathrm{Si}$ substrates. The sensitized $\mathrm{ZnO} \mathrm{NW}$ electrodes were studied by electron microscopy, Raman and PL spectroscopies, and spectral and relaxation photocurrent measurements. The Raman spectra confirm that the complexes were effectively anchored to the $\mathrm{ZnO} N W$ s through one of the pendant nitrile groups of the bipyridyl ligands. The nanostructured morphology of the $N W$ electrodes was maintained so that their light trapping characteristics were preserved. The Ru complexes were found to be excellent sensitizers of the $\mathrm{ZnO} N W s$, improving by orders of magnitude their photocurrent in the visible region. The Fe-based complex of formula [Fe(Mebpy$\left.\mathrm{CN})_{3}\right]\left(\mathrm{PF}_{6}\right)_{2}$ was also tested; however it did not show any sensitizing effect. An order of magnitude shortening of the persistent photocurrent relaxation times (after the illumination is interrupted) was found to occur upon successful sensitization of the ZnO NWs with the Ru complexes. This effect is interpreted in terms of hole traps at $\sim 1 \mathrm{eV}$ above the $\mathrm{ZnO}$ valence band edge, which are lowered by 50-60 meV in the soaked samples due to screening of the trap centers provided by the extra photoexcited charge carriers transferred from the sensitizing complex to the NWs.
\end{abstract}

\section{Introduction}

The increasing global energy demands and the need to find more efficient and cost-effective renewable energy sources have led to the development of new materials with optoelectronic properties relevant for energy conversion. $\mathrm{Si}$ is currently the most used material in the manufacture of commercial solar cells. However, high manufacturing cost and the low band gap of Si (1.12eV), which derives in a severe efficiency limit due to high portions of the solar optical energy lost into heat [1], has motivated the development of new generations of solar cells.

One of the most promising alternatives is the Grätzel or dye-sensitized solar cell (DSSC), which produces electricity from the sun radiation through a photo-electrochemical principle [2]. Advantages of this technology reside in being cost effective, easy to implement, and that cells can 
be made to be semiflexible and semitransparent. In a DSSC, the semiconductor acts as an electrode and as such it can be nanostructured to become a convenient scaffold for dye molecules designed to be efficient visible light absorbers [3]. The most frequently used semiconductor in this cell type has been $\mathrm{TiO}_{2}$ [2] in different morphologies, such as nanoparticles [4]-[7] and nanowires [8]-[11]. Up to now, DSSCs with as high as $12 \%$ photovoltaic power conversion efficiency have been developed using $\mathrm{TiO}_{2}$ mesoporous nanoparticulate electrodes [12].

Recently, $\mathrm{ZnO}$ semiconductor has attracted great attention as a promising candidate for DSSC applications [13]. Among the very interesting properties of $\mathrm{ZnO}$ are its direct bandgap of $3.37 \mathrm{eV}$, carrier mobility and electron diffusion coefficient higher than in $\mathrm{TiO}_{2}$, low production and environmental costs [14], and high environmental stability [15]-[18]. In addition, ZnO can be easily grown in a wide variety of morphologies such as nanowires, nanotubes, nanosheets, nanoparticles; and nanoflowers [19]-[22], and can be combined with other materials in composites and core-shell systems [23],[24].

As for the dye, systems based on the cis-[Ru( $\left.\left.\left(\mathrm{LH}_{2}\right)_{2}(\mathrm{NCS})_{2}\right)\right](\mathrm{L}=4,4$ '-dicarboxy-2,2'-bipyridine), sensitizer adsorbed onto nanostructured $\mathrm{TiO}_{2}$ films are currently the most extensively studied and the ones used in the most efficient DSSCs [2], [25]. Nevertheless, for ZnO, many other dyes have been proposed and tried, such as chlorophyll [26], [27], phthalocyanines/ [28], rhodamine B [29], coumarins [30], rose-bengal [31], $\mathrm{Cu}(\mathrm{I})-$ [32] and $\mathrm{Ru}(\mathrm{II})$-complexes [33], and some encouraging results have been obtained [34]-[37]. Power conversion efficiency $\eta$ of as high as $7.5 \%$ has been reported for hierarchical assembled $\mathrm{ZnO}$ nanocrystallites sensitized with $c i s-\left[\mathrm{Ru}\left(\mathrm{LH}_{2}\right)_{2}\left(\mathrm{NCS}_{2}\right]\right.$, known as N3 dye [38]. Ruthenium polypyridyl complexes appear as very appealing alternatives due to their excellent photosensitizing properties: high absorptivities in the visible region, long lifetimes of their lowest energy triplet excited states, and relatively high thermal stabilities [39]. In addition, these sensitizers can be readily anchored to the semiconductor surface through carboxylic acid groups [40]. However, the carboxylic anchored complexes have been often shown to be prone to decomposition processes, such as hydrolysis, which are detrimental to the device stability [41].

Recently [42], new sensitizers based on ruthenium polypyridyl complexes have been reported where the bpy ligands (bpy $=2,2$ '-bipyridine) were replaced by Mebpy-CN ligands (Mebpy-CN = 4-methyl-2,2'-bipyridine-4'-carbonitrile) coordinated to the metallic center. In these complexes, nitrile groups in the periphery of the polypyridyl ligands act as the anchoring groups preserving the integrity of the $\mathrm{ZnO}$ nanostructures. Considering that the lifetimes of excited states can be increased by increasing the number of nitrile groups [43], the number of ligands was varied. The new series of ruthenium complexes, of formula $\left[\mathrm{Ru}(\mathrm{bpy})_{3-\mathrm{x}}(\mathrm{Mebpy}-\mathrm{CN})_{\mathrm{x}}\right]^{2+}(\mathrm{x}=1-3)$ described in [42], present lifetime and quantum yield of emission of the lowest ${ }^{3}$ MLCT excited state increasing steadily when going from $x=1$ to $x=3$ (RuL1, RuL2, and RuL3, respectively). These three complexes have been adsorbed in $\mathrm{TiO}_{2}$ nanoparticulate electrodes [44], showing very good charge transfer properties and good behavior as electrode in a DSSC prototype. A similar complex based on Fe, of formula $\left[\mathrm{Fe}(\mathrm{Mebpy}-\mathrm{CN})_{3}\right]\left(\mathrm{PF}_{6}\right)_{2}$, has also been reported [45], but its performance on a semiconductor surface has not been yet been tested.

In this work, we report the fabrication of $\mathrm{ZnO}$ nanowire-based electrodes sensitized with the three $\mathrm{Ru}$ complexes RuL1, RuL2 and RuL3 and study their sensitizing properties, in particular the electronic transfer between the complex and the semiconductor surface using electrical and optoelectrical measurements. A $\mathrm{ZnO}$ nanowire electrode with adsorbed FeL3 was also studied. We found that the $\mathrm{Ru}$ complexes lead to large increases in the measured $\mathrm{ZnO}$ photocurrents, evidencing their excellent sensitizing properties. This is important for future use of $\mathrm{ZnO}$ in DSSCs because the $\mathrm{Ru}$ complexes with nitrile groups as ligands used here eliminate decomposition problems found in carboxylic anchored complexes used previously. In addition, we find an order of magnitude shortening of the $\mathrm{ZnO}$ persistent photocurrent relaxation times for the successfully sensitized 
samples. These results are promising for future developments of efficient $\mathrm{ZnO}$ nanowire-based dyesensitized solar cells and contribute to the understanding of photoconductivity phenomena in surface modified $\mathrm{ZnO}$ nanomaterials.

\section{Experimental details}

The $\mathrm{ZnO}$ nanowires (NWs) were fabricated through a vapor transport method, under controlled ultra-high purity $\mathrm{Ar}$ and $\mathrm{O}_{2}$ flows on Au-nanocluster covered, electrically insulating $\mathrm{SiO}_{2} / \mathrm{Si}$ substrates, as described in [20-22][1], [2]. The source-to-substrate distance within the tube furnace $(25 \mathrm{~cm})$ and the $\mathrm{O}_{2}$ flow rate $(3 \mathrm{sccm})$ were chosen to produce a dense interconnected $\mathrm{ZnO}$ NWs network with electrical resistance in the $\sim 10^{2} \mathrm{M} \Omega$ range [21]. The source temperature was $1100^{\circ} \mathrm{C}$ and the Ar flow rate was $125 \mathrm{sccm}$. Five $\mathrm{ZnO} \mathrm{NW}$ samples were made under identical growth conditions. One was kept as a reference, while the other four were soaked with each one of the polypyridyl $\mathrm{Ru}$ complexes RuL1, RuL2 and RuL3 and the FeL3 complex. A detailed physicochemical characterization of the Ru sensitizers has been presented in [42], [44], [46]: they have a $\mathrm{Ru}$ atom coordinated to bipyridyl ligands with pendant nitrile groups that act as "anchoring units". The absorption spectra of the RuL1, L2 and L3 complexes in acetonitrile are presented in [42], and that of the FeL3 complex in [45].

Soaking of the ZnO NWs was carried out by dipping each ZnO NWs sample within a different complex solution during $24 \mathrm{hs}$. Then, samples were dried in atmospheric air at room temperature and finally rinsed with acetonitrile.

The samples morphologies were studied with a Zeiss Supra 55VP scanning electron microscope. Photoluminescence (PL) spectra were obtained at room temperature under atmospheric air using the $325 \mathrm{~nm}, 15 \mathrm{~mW}$ line from a $200 \mathrm{~mW}$ KIMMON IK Series He-Cd LASER as the excitation source, and an AvaSpec-ULS3648 grating-CCD system for detection. Raman spectra were recorded using a Raman DXR spectrometer from Thermo Scientific equipped with a binocular Olympus Microscope.

For electrical and opto-electrical measurements, two co-planar Au contact pads $\sim 1.5 \mathrm{~mm}$ apart were Ar sputter-deposited on each sample. Then, Au wires were connected to the Au pads using Ag paint. The electrical characterization was made with this two-point probe configuration in rough vacuum from a rotary vane pump ( 100 mTorr). Current-voltage (IV) curves were obtained by voltage scanning between $-1 \mathrm{~V}$ and $1 \mathrm{~V}$ using a Agilent $663 \mathrm{~B}$ voltage source and monitoring the current by measuring the voltage across a test resistance connected in series with the sample using a Keithley 182 nanovoltimeter ( $1 \mathrm{nV}$ resolution). Photocurrent (PC) experiments were carried out by measuring the current in the sample with the same setup while illuminating it with an excitation source consisting of a Xenon Oriel 6267 arc lamp (free of ozone emission), quartz lenses and a computer controlled monochromator (Cornerstone 74000) provided with water and a series of second order diffraction high-pass filters. In a first type of experiments, the illumination wavelength was scanned between 300 and $700 \mathrm{~nm}$ to obtain photocurrent spectra. In a second measurement, each sample was illuminated at a fixed wavelength using a LED at $\sim 400 \mathrm{~nm}$ with $\sim 5 \%$ spectral definition (estimated irradiance flux density at the samples of $\sim 10 \mathrm{~mW} \mathrm{~cm}^{-2}$ ) during 60 minutes; then the illumination was interrupted and the PC relaxation in the dark was recorded, as in [47].

\section{Results}

Figure 1 a) and b) show cross-section SEM images from bare $\mathrm{ZnO} \mathrm{NWs}$ on the $\mathrm{SiO}_{2} / \mathrm{Si}$ substrates, and $\mathrm{ZnO} \mathrm{NWs}$ sensitized with RuL1, respectively. The $\mathrm{ZnO}$ NWs are preferentially oriented perpendicular to the substrate with wide angular dispersion, and are about $1 \mu \mathrm{m}$ long and $60 \mathrm{~nm}$ thick. These NWs grow after the formation of a thin, porous $\mathrm{ZnO}$ layer, which is expected for these growth conditions [20-22][2]. After soaking the samples with the complexes [Fig. 1 b)], the 
nanostructured morphology is maintained through a conformal coating of the NWs with a thin $(\sim 10$ $\mathrm{nm}$ ) solid complex layer. Similar results are observed for all other soaked ZnO NWs samples. The preservation of the "brush type" morphology dictated by the NWs after the soaking procedure, achieved here through the deposition of thin, conformal complex layers, is very important to maintain the low reflectance and high absorbance of the electrode that results from light trapping by multiple reflections between the NW lateral walls. This is of great relevance for the application of the electrode in solar cell devices.
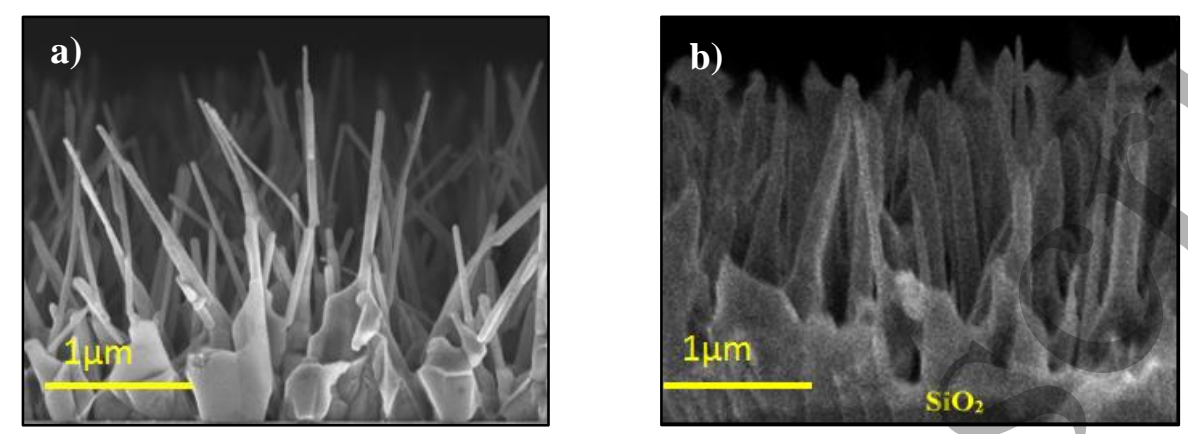

Figure 1: SEM images of a) reference sample of $\mathrm{ZnO} \mathrm{NWs}_{\text {on }} \mathrm{SiO}_{2} / \mathrm{Si}$, and b) $\mathrm{ZnO} \mathrm{NWs}+\mathrm{RuL1}$.

Anchoring through a nitrile group of all the complexes adsorbed on the surface of $\mathrm{ZnO}$ nanowires was evidenced by Raman spectra, as shown in Figure 2 (a-d). Indeed, all species display a weak band (indicated by arrows in the Figure) at $v=2330 \mathrm{~cm}^{-1}$, which is absent in the isolated complexes. This band corresponds to a stretching mode, $v(\mathrm{C} \equiv \mathrm{N})$, of a nitrile group bonded to the $\mathrm{ZnO}$ surface and is shifted $90 \mathrm{~cm}^{-1}$ to higher frequencies when compared to the value of the pure complexes $(v=$ $2240 \mathrm{~cm}^{-1}$ ). The same effect was already observed when sensitizing $\mathrm{TiO}_{2}$ mesoporous films with these species [44] and was attributed to coordination of the free $\mathrm{N}$ of the nitrile group to a metallic center on the surface. For RuL1, since there is only a single nitrile group, the nitrile band $v(C \equiv N)$ disappears completely from its original position in the Raman spectrum for the sensitized $\mathrm{ZnO}$ due to the bonding of this nitrile group to the semiconductor surface. In contrast, for FeL3, RuL2 and RuL3, bands corresponding to $v(\mathrm{C} \equiv \mathrm{N})$ of non-anchored nitrile groups appear at the same value as for the free complexes $\left(v=2240 \mathrm{~cm}^{-1}\right)$, indicating that (as may be expected) only one nitrile group coordinates to the semiconductor surface while the other (RuL2) or other two (RuL3 and FeL3) remain uncoordinated.

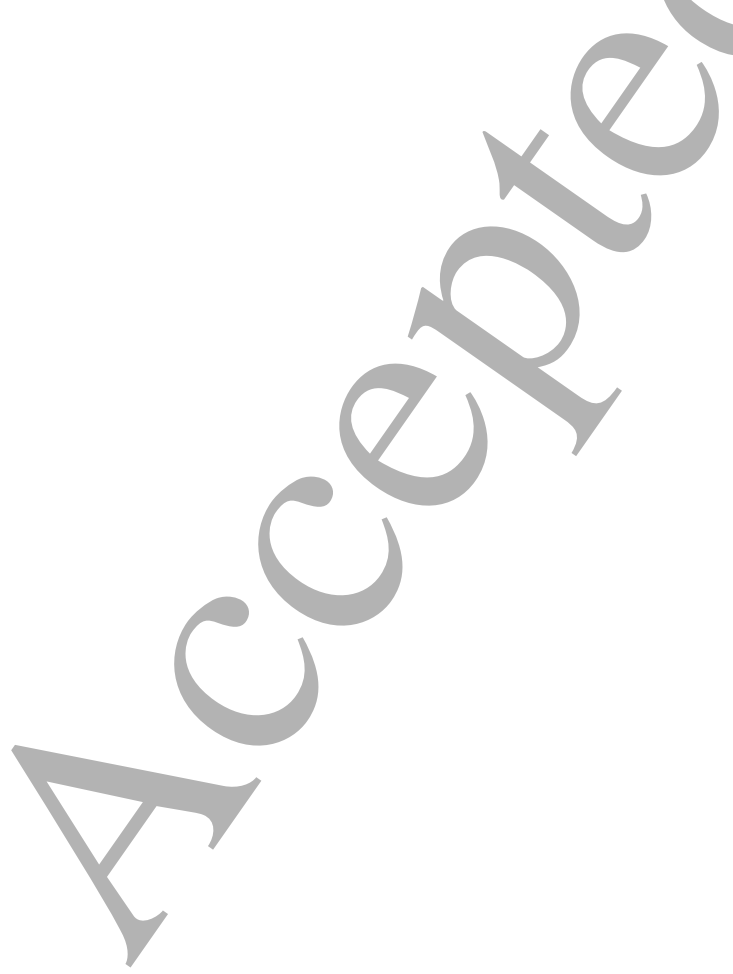



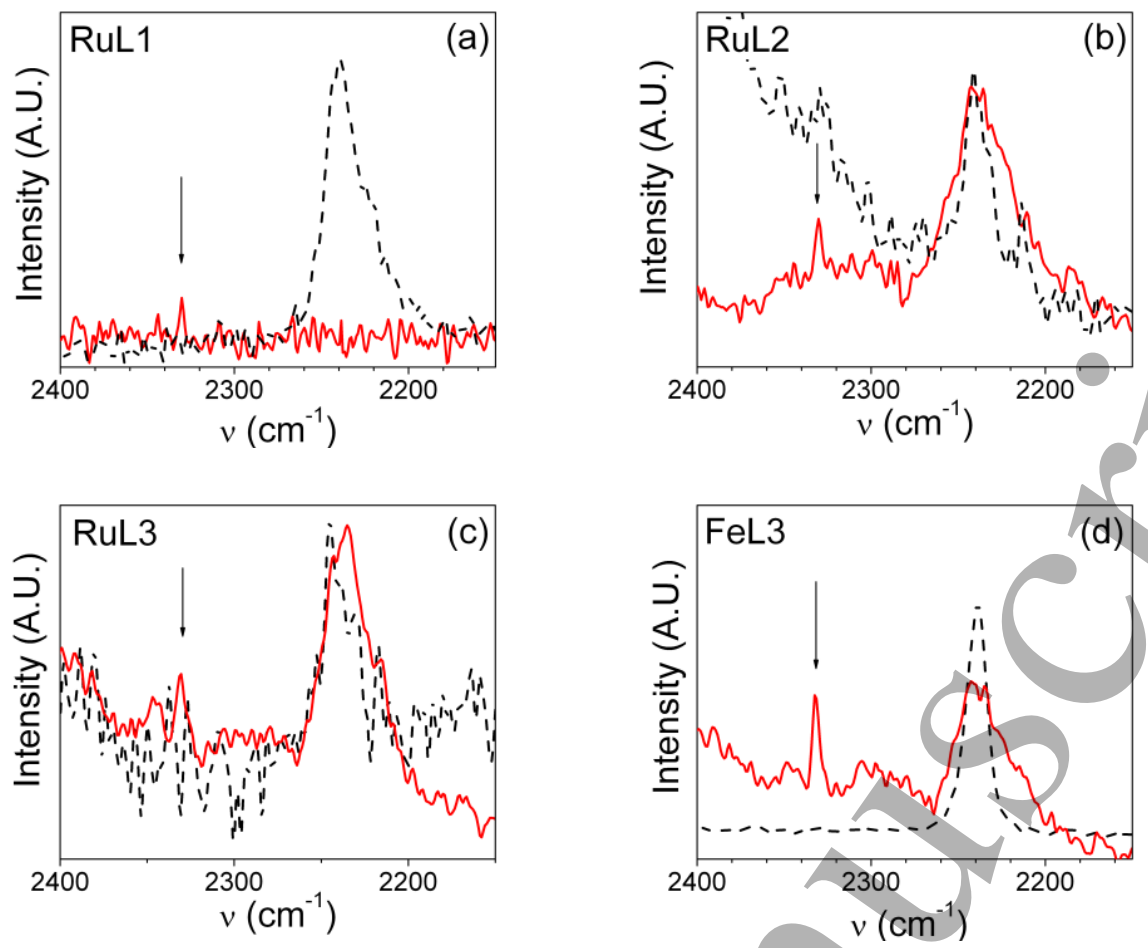

Figure 2. Red lines: Raman spectra of the complexes adsorbed onto ZnO nanowires. Dashed lines: Raman spectra of the pure complexes. (a) RuL1, (b) RuL2, (c) RuL3 and (d) FeL3.

Figures 3(a) and 3(b) show the PL spectra for the studied samples in linear and logarithmic scales. The spectrum for the unsensitized $\mathrm{ZnO} \mathrm{NW}$ sample is dominated by a band in the visible peaked at about $503 \mathrm{~nm}$ and is due to transitions involving deep defect states in the $\mathrm{ZnO}$ bandgap [20],[21]. The RuL1, RuL2 and RuL3-sensitized samples exhibit a band in the visible as well, however redshifted and less intense than the band for the reference sample. The reason for the observed changes in intensity and wavelength positions is mainly the selective absorption of portions of the $\mathrm{ZnO}$ optical emissions in the short wavelength region by the complex layers covering the samples. Indeed, the $\mathrm{Ru}$ complexes present prominent absorption bands peaked at about $450 \mathrm{~nm}$ [42] [see Figure 3(b)], which are responsible for the suppression of the intensity of the emission around this region of the PL spectra, thus leading to the observed redshift of the PL bands positions. For the case of the ZnO NW sample soaked with FeL3, the whole PL band is strongly suppressed. This is mainly because of the broad absorption band for the FeL3 complex peaked at a higher wavelength $(\sim 540 \mathrm{~nm})$ [45] [see Figure 3(b)], which overlaps the $\mathrm{ZnO}$ emission band. In addition, the complexes covering the $\mathrm{ZnO} \mathrm{NWs}$ are also expected to absorb part of the excitation power at 325 $\mathrm{nm}$ [42], [45]. We note that, while the complexes themselves have some PL (data obtained from the pure complex films, not shown), their contributions to the observed spectra in Fig. 3(a) are very small. 

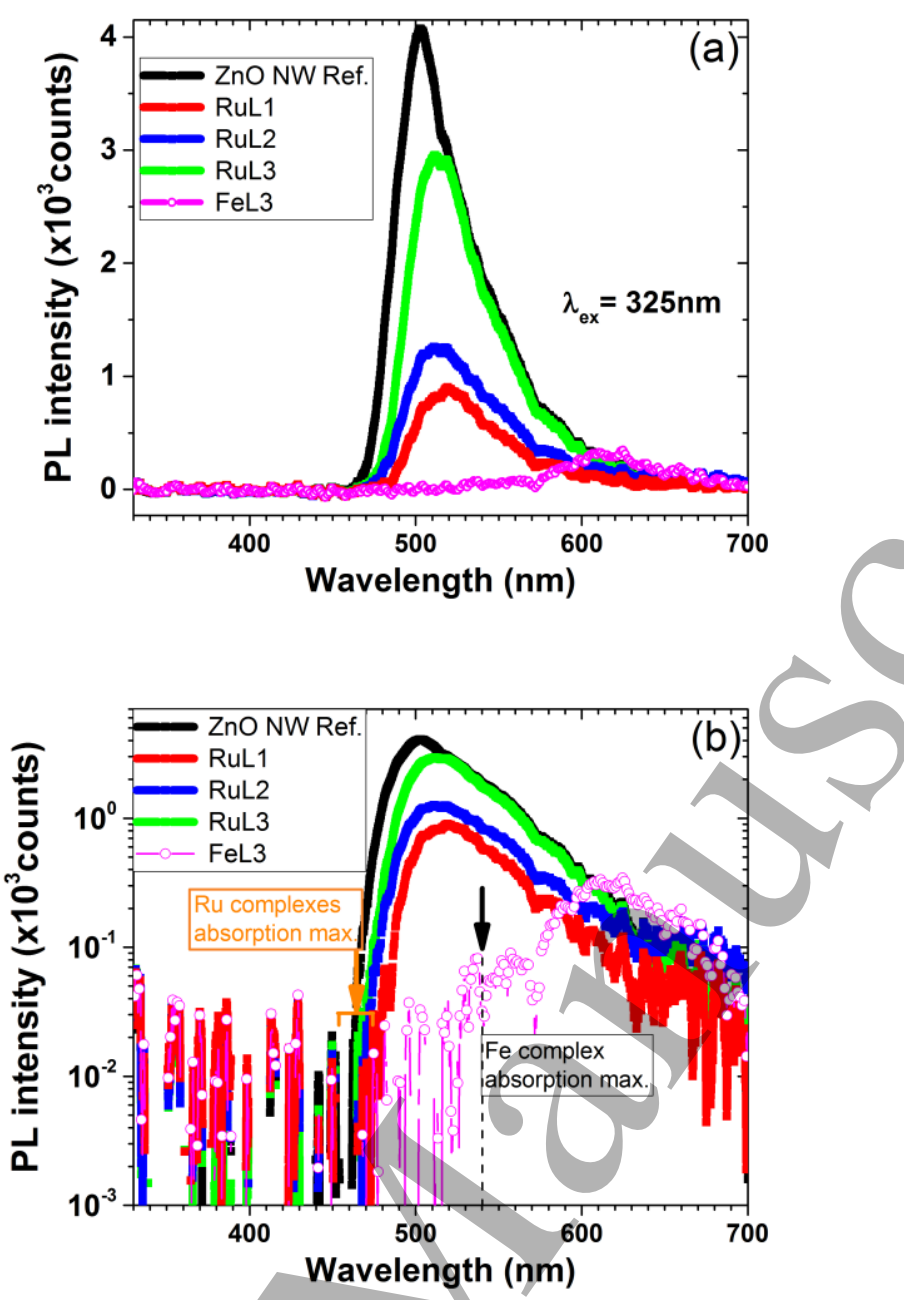

Figure 3. Photoluminescence spectra from the $\mathrm{ZnO} \mathrm{NW}$ reference sample (black) and from the $\mathrm{ZnO} \mathrm{NW}$ samples soaked with RuL1(red), RuL2 (blue), RuL3 (green) and FeL3 (pink) in (a) linear and (b) logarithmic scales. In (b), the position regions of the Ru and Fe complexes maxima of absorption bands are also shown.

The dark I- V curve for the reference ZnO NW sample is shown together with those corresponding to samples sensitized with RuL1, RuL2, RuL3 and FeL3 in Fig. 4. The I-V characteristics are linear in all cases, and the electrical resistances of the samples are obtained through the fitting of the data points with a linear function. 


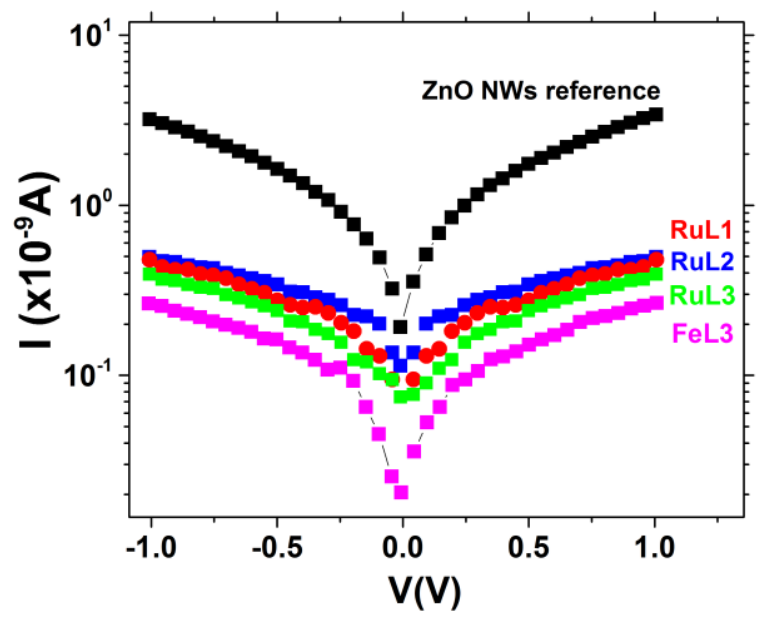

Figure 4: I-V curves (in log- linear scale) for the reference bare ZnO NWs (black) and ZnO NWs soaked with RuL1 (red), RuL2 (blue), RuL3 (green) and FeL3 (pink) samples, in air at room temperature and dark condition.

The resistances for the soaked samples are larger than for the bare ZnO NWs sample. This effect is due to the very high series resistance contributed by the thin solid complex films. We confirmed this by fabricating films of each complex on insulating $\mathrm{SiO}_{2} / \mathrm{Si}$ substrates using the dip coating method with the same parameters used for the NW samples. Then, a pair of electrical coplanar contacts was made on each film. The resulting currents were too low, indicating that the films' resistances were above the measurement limit of our equipment of about $\sim 5 \times 10^{9} \Omega$.

The PC was measured as a function of the incident photon energy by scanning the excitation wavelengths between $700 \mathrm{~nm}(1.77 \mathrm{eV})$ and $300 \mathrm{~nm}(4.13 \mathrm{eV})$. The experiments were made in atmospheric air at room temperature, while applying a voltage of $1 \mathrm{~V}$ on the samples. The results are shown in Fig. 5: in the (1.88-3.21)eV region, the PC for samples sensitized with the Ru complexes are of approximately 1.5 order of magnitude larger than for the $\mathrm{ZnO} \mathrm{NW}$ reference sample. In addition, this enhancement is seen to span a broader spectral range for the $\mathrm{ZnO} \mathrm{NW}$ sample sensitized with RuL2 the for the other two. In contrast, the data for the $\mathrm{ZnO} \mathrm{NW}$ sample soaked with FeL3 does not show any PC enhancements with respect to the reference sample.

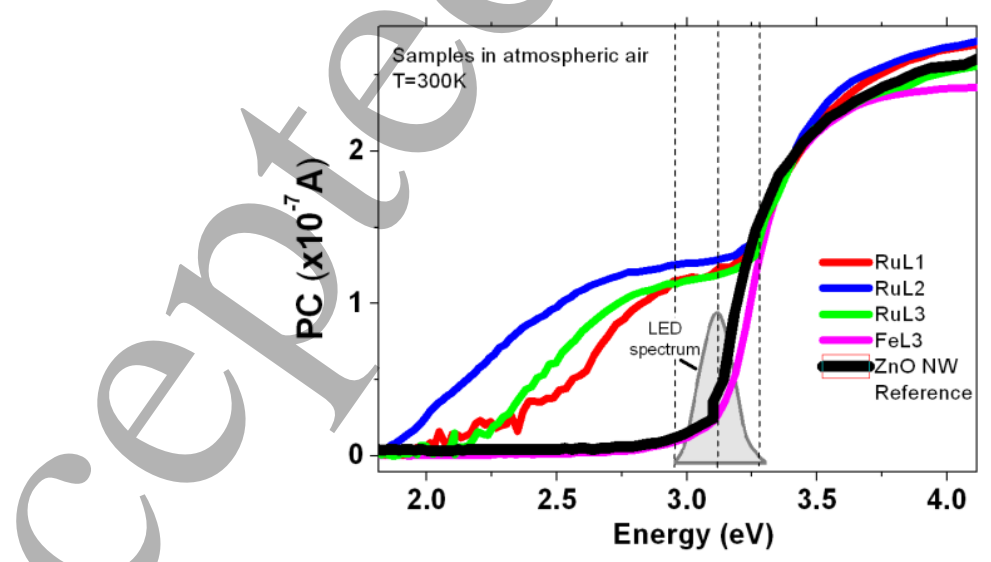

Figure 5: PC vs. incident photon energy, from unsensitized and sensitized with RuL1, RuL2, RuL3 and FeL3 $\mathrm{ZnO}$ NW samples, at room temperature and in atmospheric air. The emission spectrum from the commercial LED used as the excitation source in PC time evolution measurements is also shown in grey color. 
Since the complex layers are not photoconducting (we detected no currents in the illuminated films of pure $\mathrm{Ru}$ and $\mathrm{Fe}$ complexes deposited on the $\mathrm{SiO}_{2} / \mathrm{Si}$ substrates), the photocurrent enhancements observed in Fig. 5 are clearly due to photon absorption and charge excitation within the Ru complex layers, followed by the transfer of the photocharges to the $\mathrm{ZnO}$ NWs.

With the aim of studying the photoexcited current relaxation processes within the samples, and to analyze in what way these processes are affected by the presence of the sensitizing complexes, measurements of the PC time evolution were also performed on selected samples. The illumination in these experiments was performed with LED radiation peaked at $400 \mathrm{~nm}(3.1 \mathrm{eV})$ (see emission spectrum in Fig. 5) during 1 hour, and the PC was measured both during the illumination and after interrupting it. Fig. 6 shows the resulting PC as a function of time for the unsensitized and for the RuL2 and FeL3 sensitized samples. It is worth noting that, due to the LED emission band width of $\sim 5 \%$ around the average (peak) value (see Fig. 5), although peaked at a $\mathrm{ZnO}$ subgap region, a small portion of the emission spectrum overlaps the $\mathrm{ZnO}$ absorption edge. Hence, the PC data in Fig. 6 have contributions from carriers directly excited within the $\mathrm{ZnO}$ NWs in addition to those excited within the sensitized complex films and then transferred to the NWs.

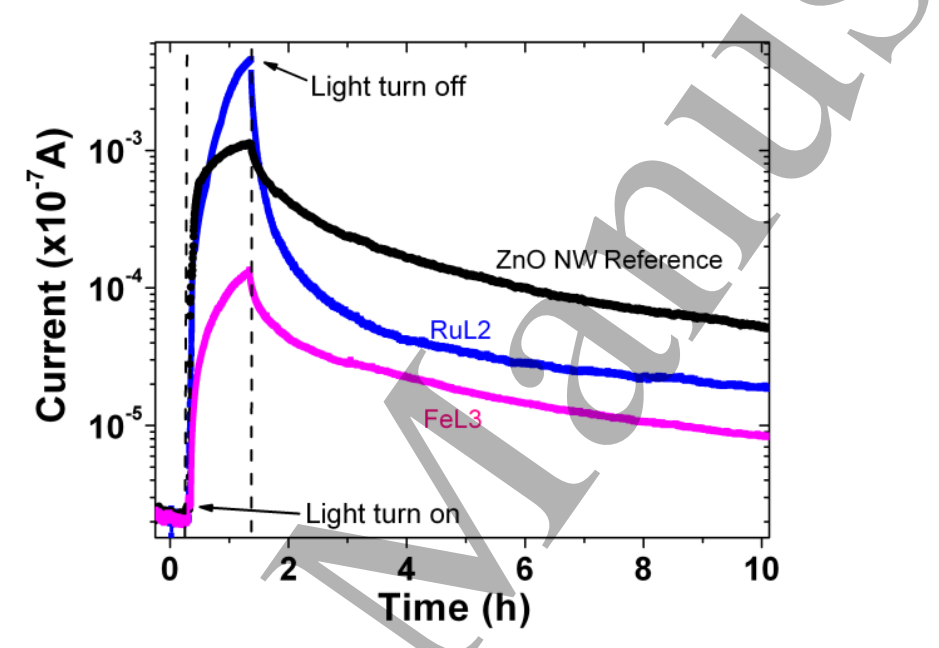

Figure 6: Photocurrent build up under $\sim 400 \mathrm{~nm}$ LED illumination and its subsequent relaxation in the dark as measured as a function of time on unsensitized (black) and sensitized RuL2 (blue) and FeL3 (pink) ZnO NW samples.

\section{Discussion}

From the SEM images (Figure 1), and from the Raman (Figure 2) and PL spectra (Figure 3), we conclude that a uniform, conformal layer of the sensitizing complexes form on the $\mathrm{ZnO}$ NWs as a result of the soaking procedure. The Raman spectra give evidence for the successful anchoring on the $\mathrm{ZnO}$ NWs through one of the nitrile groups, while the PL spectra give indirect evidence on the presence of the complex layer through the selective absorption of photons in the short wavelength part of the band emitted from defect centers within the ZnO NWs. This absorption is detected as a reduction of the PL intensity precisely around the region where the complexes have their absorption maxima. The thicknesses of the complex layers are on the order of $\sim 10 \mathrm{~nm}$. As the typical size of the complex molecules is around $1 \mathrm{~nm}$, the solid complex layers on the $\mathrm{ZnO}$ NWs comprise several molecular monolayers. Hence, photons will be efficiently absorbed within the complex layers when the samples are illuminated with photons in the visible from outside. However, for the sensitizing to be effective, the resulting excited electrons must be transferred to the $\mathrm{ZnO}$ semiconductor. Since electronic states within the complex film are localized, the excited electrons must surmount potential barriers in order to transport from monolayer to monolayer between vacant electronic sites. This results in low carrier mobilities and electrons can only travel (either by hopping or diffusion) a very short distance (on the order of $1 \mathrm{~nm}$ [48]) before they recombine. Evidence for low carrier 
mobilities within the complex layers is provided by the very low electrical currents (both in the dark and under illumination) exhibited by the complex films under bias (data not shown). Therefore, it can be stated that there will be a layer from the $\mathrm{ZnO} /$ complex interface within the sensitizer beyond which the photoexcited electrons will not be able to contribute to the PC. This issue has been studied on $\mathrm{ZnO}$ nanoparticles with different ruthenium based dyes, with varying immersion times [49]-[51]. An optimum immersion time was found for best electron injection between the dye and the semiconductor, which however depended on the complex solution concentration.

From the electrical measurements in the dark, (Fig. 4), the I-V characteristics for the reference sample are linear and symmetric around the origin, indicating that the electrical contacts are ohmic. Therefore, the measured current is not limited by a space charge region/at the contact/semiconductor interface, but mainly by the semiconductor resistance. The/measured resistance for the $\mathrm{ZnO} \mathrm{NW}$ samples is $\sim 250 \mathrm{M} \Omega$. The sensitized $\mathrm{ZnO} \mathrm{NW}$ samples present linear I$\mathrm{V}$ characteristics as well, however with much larger resistances (on the order of G $\Omega$ ). This is clearly because, as mentioned before, the deposited sensitizing layers are highly resistive due to the very low carrier mobilities.

The most important result from the present study is perhaps the demonstration of the excellent sensitization properties of the the $\mathrm{Ru}$ complexes with nitrile groups as anchoring units on $\mathrm{ZnO}$ nanowires (Figure 5). Since $\mathrm{ZnO}$ is essentially transparent in the visible region of the electromagnetic spectrum, the important enhancements of the $\mathrm{PC}$ in this spectral region for the three studied Ru complexes-sensitized samples with respect to the reference $\mathrm{ZnO}$ NW sample are clearly due to the contribution from the photoelectrons excited within the Ru complex layers, which are successfully transferred to the semiconductor. Note that, in the contact configuration used in the present work, this transfer is not in the direction of (and therefore not stimulated by) the applied electric field. The PC enhancements are limited by the fact that a fraction of the photoelectrons (those generated too far away from the interface) may not be able to reach the $\mathrm{ZnO}$ before recombining. In the case of the sample sensitized with FeL3, no PC enhancement in the visible is observed. This is probably due to the presence of a very short-lived metal-centered quintet energy state in the Fe(II)-based complex [52], where electrons can be trapped rapidly, thus inhibiting charge transfer to the semiconductor.

In order to compare the semiconductor sensitization characteristics with the optical properties of the $\mathrm{Ru}$ complexes, in Fig. 7 we have plotted the effective increase of the PC in the visible for the $\mathrm{ZnO}$ NW samples sensitized with RuL1, RuL2 and RuL3 as a function of the photon energy. The effective PC maxima are found to be very close to the respective maxima of the complexes absorption spectra [42]. Furthermore, the wider enhancement curve observed for RuL2 is consistent with the wider absorption peak for this complex as compared to those for the other two. Nevertheless, it should be noted that the spectral dependence of PC may not be determined by the complex absorption band alone, but also by the charge transport and transfer mechanisms whose details may also depend on the photon energy.

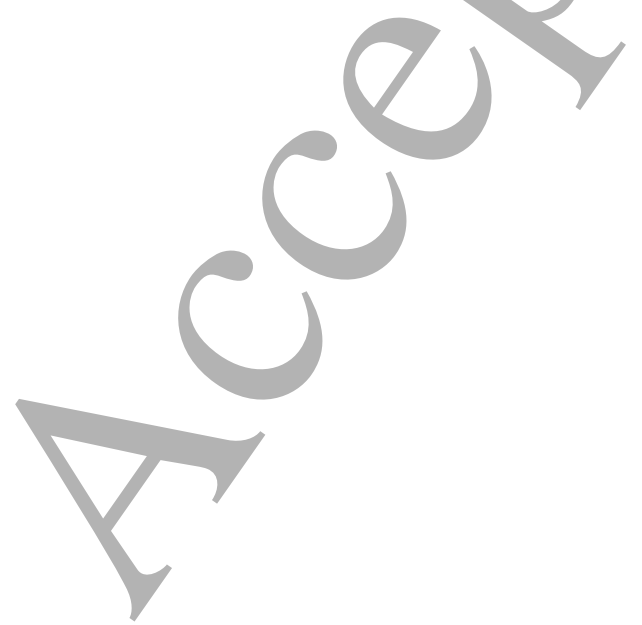




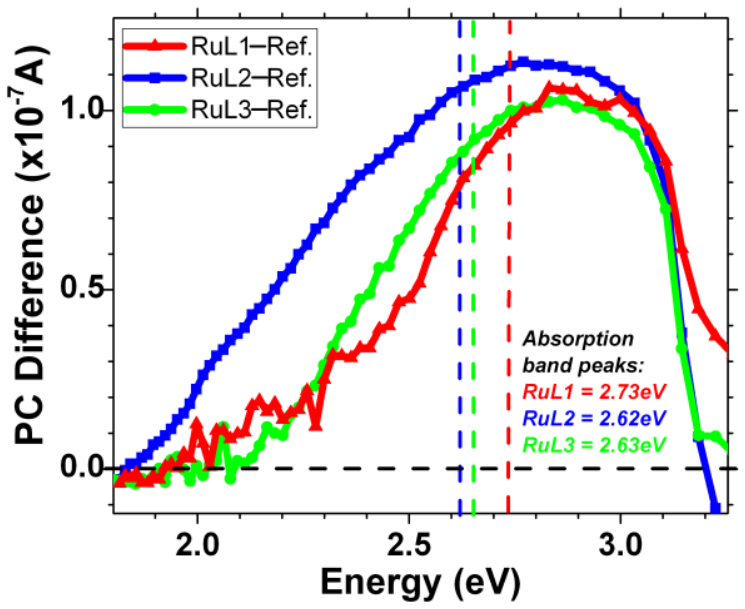

Figure 7: Difference between PC spectra for ZnO NW samples sensitized with RuL1, RuL2, RuL3 and that corresponding to the reference (unsensitized) $\mathrm{ZnO} N W$ sample.

As for the PC measurements as a function of time shown in Fig. 6, one can deduce that the resistance of the NW sample sensitized with RuL2 complex is reduced by as much as three orders of magnitude upon illumination, becoming lower than the resistance of the reference sample without complex under the same illumination. This clearly indicates that there is a strong component of photocharge generated in the complex layer that transfers to the $\mathrm{ZnO}$, which dominates over the contribution from carriers photogenerated directly there, evidencing again the excellent sensitization properties of RuL2. In contrast, in the case of the $\mathrm{ZnO} \mathrm{NW}$ sample soaked with FeL3 complex, the photocurrent reached under the same illumination conditions is lower than for the sample without complex. This confirms that, in this case, the photons absorbed in the complex are lost because fast recombination processes within the complex layer before they can hop to and cross the complex/ZnO interface. However, it is interesting to note that, for both soaked samples, the PC leveling off towards saturation upon illumination is clearly inhibited compared to the reference $\mathrm{ZnO} \mathrm{NW}$ sample. This is similar to the behavior observed on $\mathrm{ZnO} \mathrm{NW}$ samples under conditions where atmospheric air has been removed from the $\mathrm{ZnO} \mathrm{NW}$ walls, and it is related to the role of atmospheric adsorbates as electron traps [53]. When the illumination is interrupted, the current for the three cases decreases very slowly, showing a quasi-persistent behavior that is wellknown for $\mathrm{ZnO}$ [21]. In is interesting to note that the relaxation curve for the sample sensitized with RuL2 presents much faster relaxation than the data for the other samples (Fig. 6). Relaxation profiles can be analyzed to quantify changes that occur in relaxation characteristic times due to the sensitizing procedure, see Fig. 8 . 


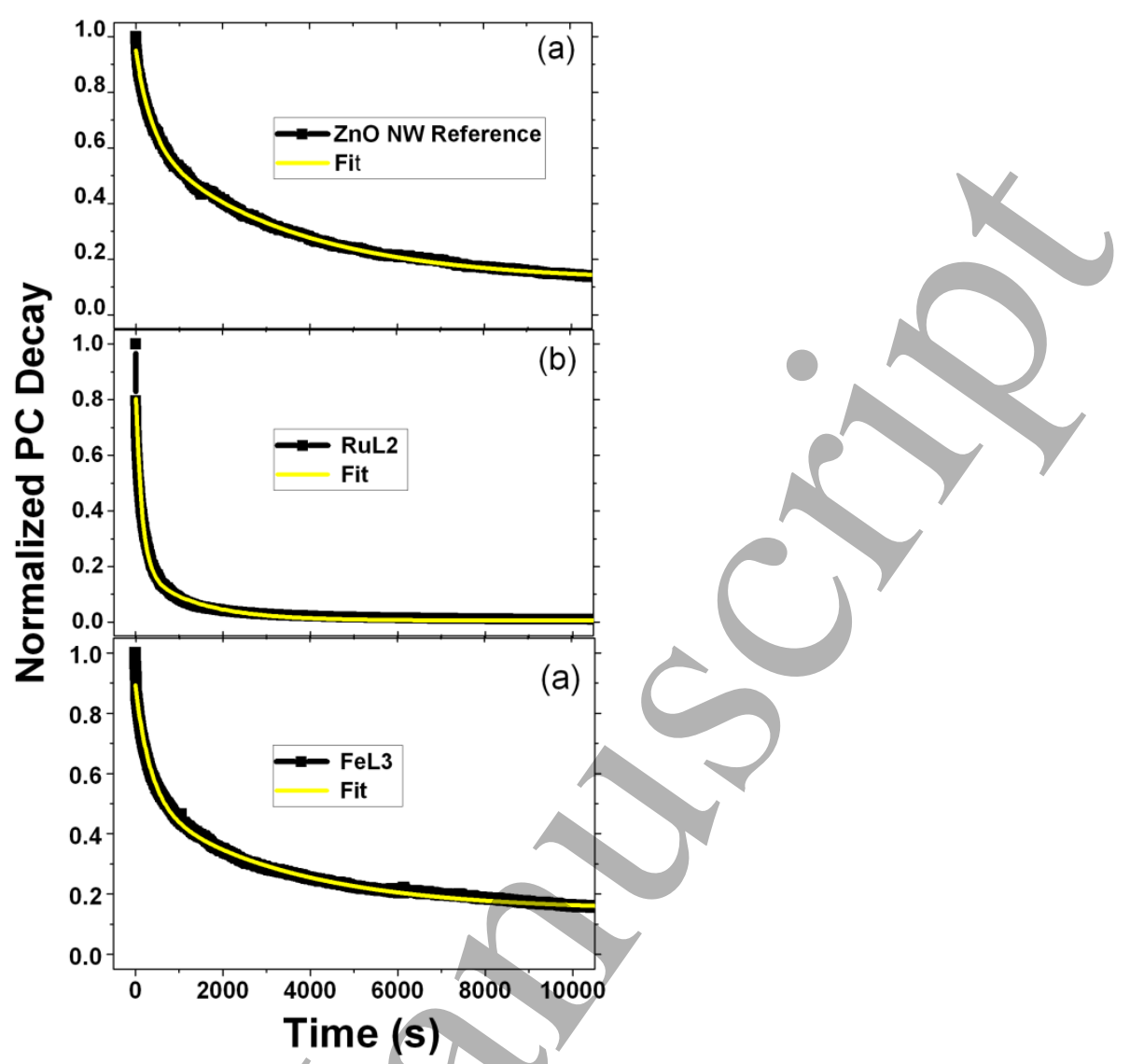

Figure 8: Normalized current relaxation curves taken from the data in Fig. 6 and plotted from the instant the illumination is interrupted (defined here as Time $=0$ ) for the (a) reference $\mathrm{ZnO}$ NW sample and for the (b)

RuL2 and (c) FeL3 soaked ZnO NW samples. Corresponding double exponential fits are also shown.

As typical for $\mathrm{ZnO}$, the decays are non-exponential. However, a double-exponential function was found to provide reasonable fits of the experimental current relaxation curves. The main parameters of the fitting function are the characteristic relaxation times $\tau_{1}$ and $\tau_{2}$, which are shown in Table I:

Table I: Characteristic relaxation times deduced from the fit of a double exponential function to the current versus time data of Fig. 8 for the reference $\mathrm{ZnO}$ NW, and for the RuL2- and FeL3-soaked ZnO NW samples.

\begin{tabular}{|c|c|c|c|}
\hline$\tau$ & Reference & RuL2 & FeL3 \\
\hline$\tau_{1}(\mathrm{~s})$ & 1120 & 165 & 815 \\
\hline$\tau_{2}(\mathrm{~s})$ & 10920 & 1000 & 11330 \\
\hline
\end{tabular}

The much shorter relaxation times for the RuL2 soaked sample $(\sim 1 / 7$ and $\sim 1 / 11$ for the fast and slow components, respectively) are probably related with the successful sensitizing process in this case. In contrast, the FeL3 soaked sample shows relaxation times that are not much different from those for the reference sample, since in this sample the sensitizing effect is negligible.

The slow relaxation of the current after illumination (i.e the quasi-persistent photoconductivity) in $\mathrm{ZnO}$ NWs is not completely understood, but it has been suggested that it may be related to the long reemission times expected for holes in deep traps in n-type wide bandgap semiconductors [54]. The model claims that, as trapped holes are reemitted back to the valence band in the depletion region, they recombine promptly with the photoexcited electrons, producing the decrease of the carrier density and the current. The problem is actually much more complex, as recombination rates may 
be affected by changes in surface traps type and density distributions due to photoinduced surface reactions, such as photodesorption of atmospheric adsorbates. However, if the thermal reemission of carriers from deep traps is assumed to be the rate-limiting step, relaxation times $\tau$ can be used to estimate the trap energies $E$ above the valence band edge, using the equation [54], [55]:

$$
\tau=\frac{1}{v} e^{E / k T}
$$

where $v$ is the attempt-to-escape frequency (approximated by the typical phonon frequency of $\sim 10^{13} \mathrm{~Hz}$ ), $k$ is the Boltzmann constant and $T$ is the absolute temperature. With this model, the energies corresponding to our experimental relaxation times are estimated and listed in Table II.

Table II: Trap energies corresponding to $\tau$ values in Table I and using Eq. 1 for the bare ZnO NWs and for ZnO NWs with RuL2 and FeL3.

\begin{tabular}{|c|c|c|c|}
\hline $\mathrm{E}$ & Unsensitized & RuL2 & FeL3 \\
\hline $\mathrm{E}_{1}(\mathrm{eV})$ & 0.96 & 0.91 & 0.95 \\
\hline $\mathrm{E}_{2}(\mathrm{eV})$ & 1.02 & 0.96 & 1.02 \\
\hline
\end{tabular}

The trap energies are in rough agreement with the value of $\sim 1 \mathrm{eV}$ deduced earlier from PC decay studies in $\mathrm{ZnO}$ films [54] and are close to bandgap state energies inferred from optical studies on $\mathrm{ZnO}$ nanoparticles [55], nanosheets [56] and thin films [57]. Some of these bandgap states have been associated with the double-ionized oxygen vacancy, which may act as a hole trap within the surface depletion region where photoholes accumulate due to the upwards band bending [58, 59]. The lower trap energies by $\sim 50-60 \mathrm{meV}$ obtained for the RuL2 complex-sensitized NW sample could be a consequence of an increased electronic screening of the trap centers produced by the extra charge injected from the complex in this case. This result is important because it shows that the present $\mathrm{Ru}$ complexes can be used to reduce the persistent photoconductivity effect for slight subgap illumination.

\section{Conclusions}

Efficient dye-sensitized $\mathrm{ZnO}$ NW electrodes have been fabricated using novel Ru complexes that use a nitrile instead of carboxylic group as anchoring unit. The electrodes were studied by electron microscopy, Raman and PL spectroscopies, and spectral and relaxation photocurrent measurements. We arrive at the following conclusions:

1) The complexes are effectively anchored through one of their nitrile ligands of their bipyridyl ligands_onto the $\mathrm{ZnO}$ NW walls after the soaking, drying and rinsing procedures reported in this work. The nanostructured morphology of the NW electrodes is preserved. This is very important so the benefits of this morphology such as light trapping for various applications, mainly in DSSCs, are not lost in the sensitization process.

2) The Ru polypyridyl complexes with pendant nitrile groups (RuL1, RuL2 and RuL3) have been shown to have excellent sensitizing properties on the ZnO NWs, improving by orders of magnitude their photocurrent in a subgap spectral region (from the violet to the yelloworange) where the $\mathrm{ZnO} \mathrm{NWs}$ have negligible absorption. The broadest sensitization wavelength span is provided by RuL2 as a result of its broader absorption band.

3) The FeL3 complex does not show any sensitizing effect on $\mathrm{ZnO}$ NWs.

4) The coating of the NWs with the Ru and Fe complexes increases the time for photocurrent buildup saturation under illumination. We propose that this effect is associated with the elimination of the $\mathrm{ZnO} \mathrm{NW}$ walls interaction with atmospheric air in the coated NWs.

5) The successful sensitization of $\mathrm{ZnO}$ NWs with $\mathrm{Ru}$ complexes leads to about a factor of 10 reductions of the relaxation times after the illumination is interrupted. This reductions are 
interpreted in terms of diminishing hole trap energies at $\sim 1 \mathrm{eV}$ above the valence band edge by $\sim 50-60 \mathrm{meV}$ due to the screening effect on trap centers provided by the extra charge transferred from the sensitizing complex layer to the $\mathrm{ZnO}$.

\section{Acknowledgments}

This work was partially funded by the Argentinean agencies Consejo Nacional de Investigaciones Científicas y Técnicas (CONICET) (grants PIP-2016-411 and PIP-2015-098), Agencia Nacional de Promoción Científica y Tecnológica (ANPCyT) (grants BID PICT 2015-0865 and PICT 20160553), Secretaría de Ciencia, Arte e Innovación Tecnológica de la Universidad Nacional de Tucumán (SCAIT) (grants PIUNT 26/E535 and PIUNT 2014/D547).

\section{References}

[1] Goetzberger A, Voss B, and Knobloch J 1998 Crystalline Silicon Solar Cells John Wiley \& Sons Ltd., Chichester.

[2] O’Regan B and Grätzel M 1991 A low-cost, high- efficiency solar cell based on dyesensitized colloidal $\mathrm{TiO}_{2}$ films Nature 353 737-740

[3] Matsumura M, Matsudaira S, Tsubomura H, Takata M, and Yanagida H 1980 Dye sensitization and surface structures of semiconductor electrodes Ind. Eng. Chem. Prod. Res. Dev. 19(3) 415-421

[4] Rashad M M, Shalan A E, Lira-Cantú M, and Abdel-Mottaleb M S A 2013 Enhancement of $\mathrm{TiO}_{2}$ nanoparticle properties and efficiency of dye-sensitized solar cells using modifiers Appl. Nanosci. 3(2) 167-174

[5] Xin X, Scheiner M, Ye M and Lin Z 2011 Surface-treated $\mathrm{TiO}_{2}$ nanoparticles for dyesensitized solar cells with remarkably enhanced performance Langmuir 27(23) 14594-14598

[6] Fan J, Li Z, Zhou W, Miao Y, Zhang Y, Hu J and Shao G 2014 Dye-sensitized solar cells based on $\mathrm{TiO}_{2}$ nanoparticles/nanobelts double-layered film with improved photovoltaic performance Appl. Surf. Sci, 319(1) 75-82

[7] Hegazy A, Kinadjian N, Sadeghimakki, B, Sivoththaman S, Allam N K, and Prouzet E 2016 $\mathrm{TiO}_{2}$ nanoparticles optimized for photoanodes tested in large area dye-sensitized solar cells (DSSC) Sol. Energy Mater. Sol. Cells 153 108-116

[8] Zhou Z-J, Fan J-Q, Wang X, Zhou W-H, Du Z-L, and Wu S-X 2011 Effect of highly ordered single-crystalline $\mathrm{TiO}_{2}$ nanowire length on the photovoltaic performance of dye-sensitized solar cells ACS Appl. Mater, Interfaces 3(11) 4349-53

[9] Maheswari Kannan D and Sreenivasan D 2015 Review of $\mathrm{TiO}_{2}$ nanowires in dye sensitized solar cell Appl, Sol. Energy 51(2) 112-116

[10] Li H, Yu Q, Huang Y, Yu C, Li R, Wang J, Guo F, Jiao S, Gao S, Zhang Y, Zhang X, Wang $\mathrm{P}$ and $\mathrm{Zhao} \mathrm{L} 2016$ Ultralong rutile $\mathrm{TiO}_{2}$ nanowire arrays for highly efficient dye-sensitized solar cells ACS Appl. Mater. Interfaces 8(21) 13384-91

[11] Roh D, Patel R, Ahn S, Kim D and Kim J 2011 Preparation of $\mathrm{TiO}_{2}$ nanowires/nanotubes using polycarbonate membranes and their uses in dye-sensitized solar cells Nanoscale 3(10) 4162-9

[12] Yella A, Lee H W, Tsao H N, Yi C, Chandiran AK, Nazeeruddin M K, Diau EW, Yeh C Y, Zakeeruddin S M and Grätzel M 2011 Porphyrin-sensitized solar cells with cobalt (II/III)based redox electrolyte exceed 12 percent efficiency Science 334 (6056) 629-634 
[13] Chandiran A K, Abdi-Jalebi M, Nazeeruddin M K, and Grätzel M 2014 Analysis of electron transfer properties of $\mathrm{ZnO}$ and $\mathrm{TiO}_{2}$ photoanodes for dye-sensitized solar cells ACS Nano, 8(3)2261-68

[14] Djurisić A B, Ng A M C, and Chen X Y 2010 ZnO nanostructures for optoelectronics: Material properties and device applications Prog. Quantum Electron. 34(4) 191-259

[15] Zhang Q, Dandeneau C S, Zhou X Y and Cao G Z 2009 ZnO Nanostructures for DyeSensitized Solar Cells Adv. Mater. 21(41) 4087-4108

[16] Apostolopoulou A, Karageorgopoulos D, Rapsomanikis A and Stathatos E 2016 Dyesensitized solar cells with zinc oxide nanostructured films made with amine oligomers as organic templates and gel electrolytes J. Clean Energy Technol. 4(5) 311-315

[17] Gonzalez-Valls I, Ballesteros B and Lira-Cantu M 2015 Vertically aligned ZnO/ $\operatorname{In}_{\mathrm{x}} \mathrm{S}_{\mathrm{y}}$ coreshell nanorods for high efficient dye-sensitized solar cells Nano 10(7) 1550103

[18] Xu F and Sun L 2011 Solution-derived $\mathrm{ZnO}$ nanostructures for photoanodes of dyesensitized solar cells Energy Environ. Sci. 4(3) 818-841

[19] Loh L and Dunn S 2012 Recent progress in ZnO-based nanostructured ceramics in solar cell applications J. Nanosci. Nanotechnol. 12 (11) 8215-30

[20] Grinblat G, Capeluto G, Tirado M, Bragas A V and Comedi D 2012 Hierarchical ZnO nanostructures: Growth mechanisms and surface correlated photoluminescence Appl. Phys. Lett. 100(23) 233116

[21] Vega N C, Tirado M, Comedi D, Rodriguez A, Rodriguez T, Hughes G M, Grovenor C R M and Audebert F 2013 Electrical, photoelectrical and morphological properties of $\mathrm{ZnO}$ nanofiber networks grown on $\mathrm{SiO}_{2}$ and on Si nanowires Mat. Res. 16(3) 597-602

[22] Vega N C, Wallar R, Caram J, Grinblat G, Tirado M, LaPierre R R and Comedi D 2012 ZnO nanowire co-growth on $\mathrm{SiO}_{2}$ and $\mathrm{C}$ by carbothermal reduction and vapour advection Nanotechnology 23(27) 275602

[23] Vega N C, Marin O, Tosi E, Grinblat G, Mosquera E, Moreno M S, Tirado M and Comedi D 2017 The shell effect on the room temperature photoluminescence from $\mathrm{ZnO} / \mathrm{MgO}$ core/shell nanowires: Exciton-phonon coupling and strain Nanotechnology 28(27) 275702

[24] Grinblat G, Bern F, Barzola-Quiquia J, Tirado M, Comedi D, and Esquinazi P 2014 Luminescence and electrical properties of single $\mathrm{ZnO} / \mathrm{MgO}$ core/shell nanowires Appl. Phys. Lett. 104(10) 103113

[25] Nazeeruddin M K, Kay A, Rodicio I, Humphry-Baker R, Mueller E, Liska P, Vlachopoulos N, and Grätzel M 1993 Conversion of light to electricity by cis-X2Bis (2,2'-bipyridyl-4,4'dicarboxylate) ruthenium (II) charge-transfer sensitizers (X $=\mathrm{CI}-, \mathrm{Br}-, \mathrm{I}-, \mathrm{CN}-$, and $\mathrm{SCN}-$ ) on nanocrystalline titanium electrodes J. Am. Chem. Soc. 115(14) 6382-90

[26] Wang X F, Kitao O, Hosono E, Zhou H, Sasaki S-I, and Tamiaki H 2010 TiO2- and ZnObased solar cells using a chlorophyll a derivative sensitizer for light-harvesting and energy conversion J. Photochem. Photobiol. A Chem. 210(2-3) 145-152

[27] Maddu A, Arjo S and Sofian I 2016 A novel visible-light photodetector based on chlorophyll-modified ZnO nanoparticles Photonics Lett. Pol. 8(3) 85-87

[28] Mattioli G, Melis C, Malloci G, Filippone F, Alippi P, Giannozzi P, Mattoni A and Bonapasta A A 2012 Zinc oxide-zinc phthalocyanine interface for hybrid solar cells J. Phys. Chem. C 116(29) 15439-48 
[29] Baviskar P K, Zhang J B, Gupta V, Chand S, and Sankapal B R 2011 Nanobeads of zinc oxide with rhodamine B dye as a sensitizer for dye sensitized solar cell application J. Alloys Compd. 510(1) 33-37

[30] Giannouli M and Fakis M 2011 Interfacial electron transfer dynamics and photovoltaic performance of $\mathrm{TiO}_{2}$ and $\mathrm{ZnO}$ solar cells sensitized with Coumarin 343 J. Photochem. Photobiol. A Chem. 226(1) 42-50

[31] Khadtare S S and Pathan H M 2014 Rose bengal sensitized ZnO photoelectrode for dye sensitized solar cell: Optimizing the performance J. Renew. Sustain. Energy 6(5) 053131

[32] Alonso-vante N, Nierengarten J-F and Sauvage J-P 1994 Spectral sensitization of large-bandgap semiconductors (thin films and ceramics) by a carboxylated bis(1,10phenanthrolíne) copper(I) complex J. Chem. Soc., Dalton Trans. 0(11) 1649-54

[33] Bedja I, Kamat P V, Hua X, Lappin A G and Hotchandani S 1997 Photosensitization of nanocrystalline $\mathrm{ZnO}$ films by bis(2,2‘-bipyridine)(2,2‘-bipyridine-4,4`-dicarboxylic acid) ruthenium(II) Langmuir 13(8) 2398-2403

[34] Hongsith K, Hongsith N, Wongratanaphisan D, Gardchareon A, Phadungdhitidhada S, and Choopun S 2015 Efficiency enhancement of ZnO dye-sensitized solar cells by modifying photoelectrode and counterelectrode Energy Procedia 79 360-365

[35] Chang W-C, Cheng Y-Y, Yu W-C, Yao Y-C, Lee C-H and Ko H-H 2012 Enhancing performance of $\mathrm{ZnO}$ dye-sensitized solar cells by incorporation of multiwalled carbon nanotubes Nanoscale Res Lett. 7(1) 166

[36] Han J, Fan F, Xu C, Lin S, Wei M, Duan X and Wang Z L/2012 ZnO nanotube-based dyesensitized solar cell and its application in self-powered devices Nanotechnology 21(40) 405203

[37] Sakai N, Miyasaka T, and Murakami T N 2013 Efficiency enhancement of ZnO-based dyesensitized solar cells by low-temperature TiCl4 treatment and dye optimization J. Phys. Chem. C 117(21) 10949-56

[38] Zhang Q, Chou T P, Russo B, Jenekhe S A and Cao G 2008 Aggregation of ZnO nanocrystallites for high conversion efficiency in dye-sensitized solar cells Angew. Chem. Int. Ed. Engl. 47(13) 2436-40

[39] Barpuzary D, Banik A, Panda A N and Qureshi M 2015 Mimicking the heteroleptic dyes for an efficient 1D-ZnO based dye-sensitized solar cell using the homoleptic ruthenium(II) dipyridophenazine complex as a photosensitizer J. Phys. Chem. C 119(8) 3892-3902

[40] Reynal A and Palomares E 2011 Ruthenium polypyridyl sensitisers in dye solar cells based on mesoporous TiO2 Eur. J. Inorg. Chem. 2011(29) 4509-26

[41] Hagfeldt A, Boschloo G, Sun L, Kloo L, and Pettersson H 2010 Dye-Sensitized Solar Cells Chem. Rev. 110(11) 6595-6663

[42] Mecchia Ortiz J H, Vega N C, Comedi D, Tirado M, Romero I, Fontrodona X, Parella T, Morán Vieyra F E, Borsarelli C D, and Katz N E 2013 Improving the photosensitizing properties of ruthenium polypyridyl complexes using 4-methyl-2,2-bipyridine-4-carbonitrile as an auxiliary ligand Inorg. Chem. 52(9) 4950-62

[43] McCusker C E and McCusker J K 2011 Synthesis and spectroscopic characterization of CNsubstituted bipyridyl complexes of Ru(II) Inorg. Chem. 50(5) 1656-69

[44] Mecchia Ortiz J H, Longo C and Katz N E 2015 Polypyridyl ruthenium complexes containing anchoring nitrile groups as $\mathrm{TiO}_{2}$ sensitizers for application in solar cells Inorg. Chem. Commun. 55 69-72 
[45] Mecchia J H and Katz N E 2017 Modulation of the absorption properties of a novel iron trisbipyridyl complex by introducing peripheral ruthenium ammines Polyhedron 135 79-85

[46] Mecchia Ortiz J H, Vega N C, Comedi D, Tirado M, Romero I, Fontrodona X, Parella T, Morán Vieyra F E, Borsarelli C D, and Katz N E 2013 Supporting Information of Improving the photosensitizing properties of ruthenium polypyridyl complexes using 4-methyl-2,2bipyridine-4-carbonitrile as an auxiliary ligand Inorg. Chem. 52(9) 4950-62

[47] Comedi D, Heluani S P, Villafuerte M, Arce R D, and Koropecki R R 2007 Power law photoconductivity time decay in nanocrystalline $\mathrm{TiO}_{2}$ thin films $J$. Phys.: Condens. Matter 19486205

[48] Keis K, Lindgren J, Lindquist S, and Hagfeldt A 2000 Studies of the adsorption process of $\mathrm{Ru}$ complexes in nanoporous $\mathrm{ZnO}$ electrodes Langmuir 16(10) 4688-94

[49] Keis K, Bauer C, Boschloo G, Hagfeldt A, Westermark K, Rensmo H and Siegbahn H 2002 Nanostructured $\mathrm{ZnO}$ electrodes for dye-sensitized solar cell applications J. Photochem. Photobiol. A: Chem. 148(1-3) 57-64

[50] Chang W C, Lee C H, Yu W C, and Lin C M 2012 Optimization of dye adsorption time and film thickness for efficient $\mathrm{ZnO}$ dye-sensitized solar cells with high at-rest stability Nanoscale Res. Lett. 7(1) 688

[51] Cannizzo A, Milne C J, Consani C, Gawelda W, Bressler Ch, Mourik F van and Chergui M 2010 Light-induced spin crossover in Fe(II)-based complexes: The full photocycle unraveled by ultrafast optical and X-ray spectroscopies Coord. Chem. Rev. 254(21-22) 2677-86

[52] Pierloot K and Vancoillie S 2008 Relative energy of the high-(5T2g) and low-(1A1g) spin states of the ferrous complexes [Fe(L)(NHS4)]: CASPT2 versus density functional theory $J$. Chem. Phys. 128(3) 34104

[53] Cammi D and Ronning C 2014 Persistent photoconductivity in $\mathrm{ZnO}$ nanowires in different atmospheres Adv. Condens. Mat. Phys. 2014184120

[54] Moazzami K, Murphy T E, Phillips J D, Cheung M C K and Cartwright A N 2006 Subbandgap photoconductivity in $\mathrm{ZnO}$ epilayers and extraction of trap density spectra Semicond. Sci. Technol. 21(6) 717-23

[55] Dijken A, Meulenkamp, Vanmaekelbergh D and Meijerink A 2000 Identification of the transition responsible for the visible emission in $\mathrm{ZnO}$ using quantum size effects J. Lumin. 90(3-4) 123-28

[56] Vempati S, Mitra S and Dawson P 2012 One-step synthesis of ZnO nanosheets: a blue-white fluorophore Nanoscale Res. Lett. 7470

[57] Vanheusden K, Warren W L, Seager C H, Tallant D R and Voigt J A 1996 Mechanisms behind green photoluminescence in ZnO phosphor powders J. Appl. Phys. 797983

[58] Ye J D, Gu S L, Qin F, Zhu S M, Liu S M, Zhou X, Liu W, Hu L Q, Zhang R, Shi Y and Zheng Y D 2005 Correlation between green luminescence and morphology evolution of ZnO films," Appl. Phys. A 81759-762

[59] Penhold T J, Szlachetko J, Santomauro F G, Britz A, Gawelda W, Doumy G, March A M, Southworth S H, Rittmann J, Abela R, Chergui M and Milne C J 2018 Revealing hole trapping in ZnO nanoparticles by time-resolved X-ray spectroscopy Nat. Commun. 9478 